\title{
Impaired fertility in women and men with chronic kidney disease
}

\author{
Piotr Kuczera ${ }^{A, B, D, F}$, Andrzej Więcek, ${ }^{E, F}$, Marcin Adamczak ${ }^{A, D-F}$ \\ Department of Nephrology, Transplantation and Internal Medicine, Medical University of Silesia, Katowice, Poland \\ A - research concept and design; B - collection and/or assembly of data; C - data analysis and interpretation; \\ $D$ - writing the article; $E$ - critical revision of the article; $F$ - final approval of the article
}

\section{Address for correspondence}

Piotr Kuczera

E-mail: pkuczera@sum.edu.pl

Funding sources

None declared

Conflict of interest

None declared

Received on May 23, 2021

Reviewed on July 4, 2021

Accepted on August 11, 2021

Published online on February 17, 2022

\begin{abstract}
Chronic kidney disease (CKD) is accompanied by a great number of comorbidities. One of the most clinically important, present in women as well as in men, is infertility. In this review paper, the entire issue of impaired fertility in women and men with CKD is discussed. In both genders, impaired fertility is caused by the interconnection of several factors. In women, these are as follows: the accumulation of uremic toxins; endocrine disorders (e.g., reduced renal clearance of different hormones, disturbed activity of the pituitary-gonadal axis); the impairment of the ovarian function; a reduced ovarian reserve; sexual function disorders; and depression. In men, quite similarly: the accumulation of uremic toxins; endocrine disorders; the impairment of spermatogenesis; direct testicular damage; erectile dysfunction (ED); and depression. The prevalence of impaired fertility increases with the degree of kidney function deterioration in women and men. The highest prevalence of these disturbances is observed in patients with CKD stage 5. Successful kidney transplantation $(K T x)$ in women reduces the accumulation of uremic toxins, restores the function of the endocrine system and improves, but does not normalize, fertility. Similarly in men, KTx restores the function of the endocrine system and improves fertility up to a point, but cannot fully reverse the morphological damage already done to the gonads by the uremia itself. Infertility is one of the important, yet sometimes depreciated complications in women and men with CKD. The etiology and pathogenesis of infertility in CKD is complicated. Kidney transplantation alleviates, but does not fully reverse fertility impairment in CKD patients.
\end{abstract}

Key words: infertility, chronic kidney disease, kidney transplantation

Cite as

Kuczera P, Więcek A, Adamczak M. Impaired fertility

in women and men with chronic kidney disease.

Adv Clin Exp Med. 2022;31(2):187-195.

doi:10.17219/acem/141188

DOI

10.17219/acem/141188

Copyright

Copyright by Author(s)

This is an article distributed under the terms of the

Creative Commons Attribution 3.0 Unported (CC BY 3.0)

(https://creativecommons.org/licenses/by/3.0/) 


\section{Introduction}

Fertility disorders occur commonly in patients with chronic kidney disease (CKD). These disorders affect both women and men with comparable severity, but in a different manner. Disturbances concerning sexual life and procreation are important clinical problems in these patients, and may lead to the worsening of the quality of their lives or the development of depression. It seems, though, that they are quite often overlooked by the clinicians dealing with CKD patients. The aim of this review paper is to describe the entirety of fertility abnormalities in women and men with CKD and after kidney transplantation (KTx), in a detailed yet concise manner, and thus support physicians in making adequate decisions concerning patients with renal diseases.

\section{Infertility in women with chronic kidney disease}

Impaired fertility is one of the important, yet sometimes depreciated comorbidities in women with advanced CKD. It is most common in women with CKD stage 5 . In women younger than 40 years of age requiring chronic hemodialysis, primary ovarian insufficiency is more prevalent than in the general population. ${ }^{1}$ Menopause occurs in these women around 4.5 years earlier as compared to healthy females. ${ }^{2,3}$ Pregnancy in women on chronic hemodialysis is rare - its prevalence is $0.3 / 100$ females/year, which is about 40 times less than in the general population., ${ }^{4,5}$ Interestingly, pregnancy is more likely to occur in women receiving renal replacement treatment (RRT) with preserved residual renal function. ${ }^{6}$

Infertility is defined as a failure to become pregnant after 1 year of regular sexual intercourse without using any

Table 1. Causes of fertility disturbances in women with chronic kidney disease (CKD)

\begin{tabular}{|l|l|}
\hline \multicolumn{1}{|c|}{ Fertility disturbances } & \multicolumn{1}{c|}{ Causes } \\
\hline Sexual function disorders & $\begin{array}{l}\text { - decrease in libido (HSDD) } \\
\text { - depression and adverse effects } \\
\text { of antidepressant medications } \\
\text { - peripheral neuropathy } \\
\text { - anemia } \\
\text { - cardiovascular disorders }\end{array}$ \\
$\begin{array}{ll}\text { Endocrine abnormalities } \\
\text { leading to irregular } \\
\text { menstrual cycles }\end{array}$ & $\begin{array}{l}\text { - hyperprolactinemia } \\
\text { - disturbed pulsatile secretion of GnRH, } \\
\text { LH and FSH }\end{array}$ \\
$\begin{array}{l}\text { Impaired ovarian function } \\
\text { (reduced ovarian reserve) }\end{array}$ & $\begin{array}{l}\text { - low estradiol concentration } \\
\text { - low AMH concentration }\end{array}$ \\
\hline
\end{tabular}

HSDD - hypoactive sexual desire disorder; GnRH - gonadotropinreleasing hormone; $\mathrm{LH}$ - luteinizing hormone; $\mathrm{FSH}$ - follicle-stimulating hormone; $\mathrm{AMH}$ - anti-Müllerian hormone. contraception. ${ }^{6}$ In the general population, the prevalence of infertility varies between $8 \%$ and $12 \%$, with the female factor of infertility contributing to more than $72 \%$ of cases in developed countries. ${ }^{7,8}$ The prevalence of infertility in women with CKD stage 5 has been reported as exceeding $90 \% .^{1}$

Impaired fertility in women with CKD may be caused by the accumulation of uremic toxins, sexual function disorders, decreased renal catabolism of different hormones, and other abnormalities of the endocrine system. Moreover, the function of the ovaries is deteriorated, which is manifested by the reduction of the ovarian reserve (Table 1). The aforementioned complications may lead to irregular, usually anovulatory menstrual cycles and significant difficulties in successful pregnancies in female CKD patients. ${ }^{9-11}$

\section{Sexual function disorders in women with chronic kidney disease}

In CKD women, the disorders of the sexual function are frequent and may arise from psychological as well as organic factors. Among chronically hemodialyzed women, 60-70\% suffer from sexual dysfunction.

Over $50 \%$ of these women complain of a significant libido decrease and a concomitant decline in the ability to reach orgasm. This causes a marked reduction in the frequency and quality of sexual intercourse, ${ }^{2,11}$ and falls into a definition of hypoactive sexual desire disorder (HSDD), which is described as a persistent absence of sexual thoughts and/or desire for and receptivity to sexual activity, and is regarded as a cause of personal distress. ${ }^{2,3,12}$ Another important psychological factor leading to sexual dysfunction in women with CKD is the coexistence of depression. ${ }^{13,14}$

Amid the organic causes of sexual dysfunction in CKD, a variety of conditions may be listed. The uremic milieu per se, peripheral neuropathy, anemia, cardiovascular diseases (CVDs), the disturbances of the endocrine system affecting the pituitary-gonadal axis, as well as the adverse effects of antidepressant medications can all contribute to the sexual derangements in these women. ${ }^{11,12}$

All of the aforementioned conditions may lead to a significant impairment of the sexual function in women with CKD. In self-reported questionnaire analyses, the magnitude of sexual dysfunction in CKD women ${ }^{14}$ was comparable to that of "post-menopausal women with sexual dysfunction", ${ }^{15}$ and was markedly higher than in women with diabetes. ${ }^{16}$ Even more significant, over $55 \%$ of the participants in a study by Peng et al. had no sexual life at all during the course of the study, so they were not counted as patients with sexual dysfunction. ${ }^{14}$ Of note, dialysis adequacy $(\mathrm{Kt} / \mathrm{V}>1.2)$ seems not to have a beneficial influence on the magnitude of sexual dysfunction in dialyzed women. ${ }^{14}$ 


\section{Endocrine disorders in women with chronic kidney disease}

Severe alterations of the endocrine gland function (i.a., the pituitary gland and the ovaries) are a frequent finding in women with CKD. They have a complex nature and may be due to improper synthesis, secretion or metabolism of different hormones, which is mostly caused by the deterioration of the kidney function. The most severe consequences of the aforementioned disturbances are anovulatory menstrual cycles and infertility. The disturbances of the hypothalamic-pituitary-ovarian axis occur early in CKD and tend to progress with the course of disease, as well as after the initiation of RRT. ${ }^{9,17}$

\section{Prolactin}

Serum prolactin (PRL) concentration is increased in $30-65 \%$ of women with CKD. The basal serum PRL concentration is usually elevated and improper diurnal rhythm of PRL secretion can be observed. Additionally, the sleep-induced bursts of PRL secretion are usually absent, although episodic secretion of PRL in the daytime has been noted.

The most prominent factor in the pathogenesis of hyperprolactinemia in women with CKD is reduced renal clearance of PRL. Also, an increase in PRL secretion in the pituitary gland, caused by inadequate dopaminergic inhibition, ${ }^{17,18}$ contributes to hyperprolactinemia in these patients. Additionally, an increase in serum PRL concentration after stimulation by thyrotropin-releasing hormone (TRH) administration is usually blunted.

In CKD women with hyperprolactinemia, amenorrhea is a frequent finding. ${ }^{9}$ An increased serum PRL concentration is one of the major factors contributing to the dysregulation of the hypothalamic-pituitary-ovarian axis. This inhibits gonadotropin secretion, leading to hypogonadotropic hypogonadism.

In a small clinical study conducted on CKD patients with hyperprolactinemia, bromocriptine treatment led to the reduction of blood pressure and left ventricular hypertrophy, along with the normalization of prolactinemia. ${ }^{19}$ Moreover, sustained treatment with erythropoietin-stimulating agents (ESAs) may also decrease serum PRL concentration in patients treated with chronic hemodialysis. ${ }^{20}$

\section{Luteinizing hormone and follicle-stimulating hormone}

In apparently healthy premenopausal females, luteinizing hormone $(\mathrm{LH})$ is secreted in a pulsatile manner. Women with CKD are characterized by the loss of pulsatile gonadotropin-releasing hormone $(\mathrm{GnRH})$ secretion in the hypothalamus, which leads to the lack of normal pulsatile LH release by the pituitary gland.

Premenopausal CKD patients are characterized by a normal or mildly elevated basal serum LH concentration, but the pre-ovulatory peak of serum LH concentration is absent. ${ }^{9}$ In healthy women, estradiol blunts the amplitude of LH pulses. In women with CKD, estradiol does not influence the serum LH concentration surge. This suggests the impairment of the physiological feedback loop and contributes to the impairment of ovulation. In consequence, the loss of normal pulsatile LH secretion in the pituitary gland in CKD leads to infertility. ${ }^{21}$

The loss of pulsatile GnRH release in the hypothalamus also affects the pituitary follicle-stimulating hormone (FSH) secretion. Nevertheless, in contrast to LH, serum FSH concentration usually is normal or just slightly elevated in most premenopausal females with CKD. This causes a decrease in the FSH/LH ratio, which is also the reflection of a significant hypothalamic-hypophyseal dysregulation in women with CKD. ${ }^{11}$

\section{Estrogens and progesterone}

In female CKD patients, serum estradiol concentration may be normal, but more often decreased, and is consistently lower in women with CKD and concomitant hyperprolactinemia. In the luteal phase of the menstrual cycle, serum progesterone concentration is decreased as a result of defective luteinization of the follicles. ${ }^{9}$

One of the major clinical consequences of a decreased serum estrogen concentration are bone disorders. ${ }^{22}$ Patients with amenorrhea present not only low serum estrogen concentration, but also lower bone mineral density (BMD), as compared to women requiring RRT that do not have menstruation disorders. The results of small clinical interventional studies suggest that treatment with transdermal estradiol (with the cyclic addition of progestin - norethisterone acetate) or treatment with selective estrogen receptor modulators (SERMs, e.g., raloxifene) may increase the BMD of the lumbar spine in postmenopausal women on chronic hemodialysis. ${ }^{23}$ Still, taking into consideration the potential adverse cardiovascular effects of hormonal replacement therapy (HRT), it has to be underlined that currently no conclusive results of long-term clinical studies on SERMs and HRT in women with CKD are available.

\section{Anti-Müllerian hormone}

Besides the aforementioned sexual function disorders and alterations of the hypothalamic-pituitary-gonadal axis, also impaired ovarian function per se is a prominent cause of fecundity disorders in CKD women. ${ }^{3}$ One of the indicators of ovarian impairment is a reduced ovarian reserve. The ovaries are susceptible to injury from a variety of factors, which is due to the limited number of germinal cells present in the ovaries and their inability to regenerate. The term "ovarian reserve" refers to the remaining endowment of resting and primary ovarian follicles. It is used to define the quality and quantity of follicles that are present in the ovaries at a given time. ${ }^{24}$ 
One of the best markers of the ovarian reserve in women with preserved renal function is the serum concentration of anti-Müllerian hormone (AMH). Anti-Müllerian hormone is a $140 \mathrm{kDa}$ glycoprotein that circulates as a dimer. It is mostly synthesized by granulosa cells that surround each oocyte in primary, preantral and small antral follicles until they reach a diameter of $6-8 \mathrm{~mm} .{ }^{25,26}$ The abrupt decrease of AMH expression is observed in larger follicles, as the follicle becomes dominant. The most important physiological function of AMH is the inhibition of the excessive recruitment of primordial follicles and the inhibition of the growth of preantral and antral follicles, which is mediated through the reduction of their sensitivity to FSH stimulation. This takes place in the follicular phase of the menstrual cycle and leads to the selection of a dominant follicle. The quantity of resting primordial follicles that remain intact in the ovaries determines the ovarian reserve. ${ }^{26-28}$

Physiological monthly serum sex hormone concentration fluctuations do not influence serum AMH concentration in women. It tends to be constant during the entire menstrual cycle. ${ }^{28,29}$ Serum AMH concentration reflects the number of growing follicles and is proportional to the pool of primordial follicles. That is why serum AMH concentration is considered to be one of the best markers of the ovarian reserve. Physiologically, the highest serum AMH concentration is observed after puberty (in women around 25 years of age). Then, serum AMH concentration decreases with age at a rate of about $6 \%$ per year until circulating $\mathrm{AMH}$ is virtually undetectable in postmenopausal woman. This decrease in serum AMH concentration is tightly connected to a decrease in the number of growing follicles. ${ }^{29,30}$

The diminishing serum AMH concentration may be an indicator of either physiological or premature aging of the gonads. ${ }^{29,31}$ The results of our clinical study showed significantly lower serum AMH concentration in hemodialyzed women with regular menstrual cycles than in agematched regularly menstruating females from the control group. ${ }^{10}$ This seems to suggest that a decrease in $\mathrm{AMH}$ secretion by the damaged granulosa cells and the reduction of the ovarian reserve are the most pronounced causes of diminished fertility in women with CKD. The results seem to imply that infertility in CKD women is at least partially caused by the damage of the ovaries due to uremic toxins. ${ }^{10}$ Later studies regarding this topic showed similar results, ${ }^{31,32}$ with an additional finding that serum AMH concentration seems not to depend on the presence of proteinuria. ${ }^{31}$

\section{Impaired fertility in women after kidney transplantation}

The results of various clinical studies suggest that successful KTx tends to improve, but not normalize, female fertility. Pregnancy is 4 times more common in women with well-functioning kidney allografts than those requiring chronic hemodialysis. Still, it is about 10 times less probable than in the general population. Kidney transplantation usually restores the sexual function and decreases menstrual cycle disturbances. It also tends to normalize the secretion of sex hormones. It was demonstrated that the serum concentrations of LH, FSH and PRL in women after successful KTx are similar to those in healthy controls. It seems that the restoration from the uremic milieu to normal endocrine environment leads to normal maturation of the Graafian follicles, normal ovulation and luteinization. ${ }^{11,33,34}$

However, it is important to stress that women after successful KTx are characterized by significantly lower serum AMH concentration as compared to healthy females. This gives a rationale for an assumption that although KTx leads to the alleviation of the hypothalamus-pituitary-ovarian axis derangements, it does not restore the ovarian reserve. Therefore, it is likely that the disturbances of fertility, which are to some extent still present after KTx, are caused by the impairment of the ovarian function. This impairment of the ovaries seems to arise from the irreversible damage caused by uremic toxicity present before the transplantation procedure. ${ }^{10}$

Anti-Müllerian hormone is a protein hormone, thus it is most likely metabolized by the kidneys, like other proteins. This may explain the observed decrease in serum AMH concentration accompanying the improvement of the kidney function after a uccessful KTx. However, this hypothesis needs to be confirmed in cross-sectional studies amidst patients with different stages of CKD and in experimental animal studies.

\section{Infertility in men with chronic kidney disease}

As mentioned before, infertility is defined as the inability to conceive after a 1-year period of regular intercourse. In the general population, approx. $30-50 \%$ of infertility cases can be attributed to male factors. ${ }^{35}$ Little is known about the prevalence and exact pathogenesis of fertility disorders in men with CKD. It seems, though, that they stem from the interconnection of 3 major causes: erectile dysfunction (ED); endocrine abnormalities; and testicular morphology alterations/impaired spermatogenesis (Table 2).

\section{Erectile dysfunction}

The prevalence of ED in CKD patients reaches 70-80\%, which is much more than in the general population. Erectile dysfunction is most commonly observed in men requiring RRT. ${ }^{36,37}$ The nature of this alteration is complex, as physiological, psychological and organic factors are involved in its pathogenesis. The most important causes of ED are cardiovascular and nervous system alterations. 
Table 2. Causes of fertility disturbances in men with chronic kidney disease (CKD)

\begin{tabular}{|c|c|}
\hline $\begin{array}{c}\text { Fertility } \\
\text { disturbances }\end{array}$ & Causes \\
\hline ED & $\begin{array}{l}\text { - cardiovascular disorders } \\
\text { - decrease in the NO synthesis } \\
\text { - autonomous nervous system dysfunction } \\
\text { - depression and adverse effects of antidepressant } \\
\text { medications } \\
\text { - peripheral neuropathy } \\
\text { - anemia } \\
\text { - zinc deficiency } \\
\text { - adverse effects of antihypertensive medications } \\
\text { - obesity } \\
\text { - smoking }\end{array}$ \\
\hline $\begin{array}{l}\text { Endocrine } \\
\text { abnormalities }\end{array}$ & $\begin{array}{l}\text { - low TT and FT concentrations } \\
\text { - elevated LH and FSH concentrations } \\
\text { - hyperprolactinemia }\end{array}$ \\
\hline $\begin{array}{l}\text { Testicular } \\
\text { damage/impaired } \\
\text { spermatogenesis }\end{array}$ & $\begin{array}{l}\text { - decreased number and motility of sperm cells } \\
\text { - Sertoli cell atrophy } \\
\text { - testicular fibrosis } \\
\text { - low AMH concentration } \\
\text { - morphological extra-testicular disturbances }\end{array}$ \\
\hline
\end{tabular}

ED - erectile dysfunction; NO - nitric oxide; TT - total testosterone; FT - free testosterone; LH - luteinizing hormone; FSH - follicle-stimulating hormone; $\mathrm{AMH}$ - anti-Müllerian hormone.

Other important contributing conditions are anemia, erythropoietin (EPO) and zinc deficiency, as well as coexisting diseases and their pharmacotherapy.

Chronic kidney disease is often accompanied by CVDs. One of the critical components of CVD is endothelial dysfunction, in which the production of nitric oxide (NO) in endothelial cells is severely compromised. Nitric oxide is a crucial player in the vasodilatation of cavernous arteries, which is necessary for the accumulation of blood in the cavernous bodies, required for the initiation and maintenance of erection. ${ }^{38,39}$ Thus, a diminished NO synthesis in the endothelium leads to the development of erectile dysfunction in this group of patients.

The amount of blood flow through the cavernous arteries is strictly orchestrated by the autonomous nervous system. In the penis flaccid state, the sympathetic nervous system is predominant and after sexual stimulation, the parasympathetic nervous system activation starts to dominate. This leads to vasodilatation and the increase of blood flow through the cavernous bodies. So unsurprisingly, autonomous nervous system neuropathy, frequently observed in uremia, contributes to the development of ED. ${ }^{40}$

Patients with CKD have a tendency to have a decreased blood hemoglobin concentration, which is most pronounced in CKD stage 5. Erythropoietin-stimulating agents are currently commonly used in these patients in order to restore the optimal hemoglobin concentration. Treatment with ESAs is also reported to have a beneficial influence on ED in CKD men. ${ }^{41,42}$ At first, this effect was attributed to the serum PRL concentration decrease caused by the treatment with ESAs; still, later studies yielded conflicting results concerning this matter. ${ }^{41,43}$ Recently, it has been proposed that ESAs may contribute to an increase in serum testosterone concentration and the regeneration of the cavernous nerve as well as antiapoptotic activity in the cavernous bodies. $^{44-46}$ These factors may lead to the decreased magnitude of ED in CKD patients treated with ESAs.

Zinc deficiency has been lately regarded as one of possible causes of EPO-resistant anemia in CKD patients. ${ }^{47}$ This phenomenon is caused by the reduced absorption in the gastrointestinal duct and direct removal during each hemodialysis session. The results of studies conducted so far demonstrate a beneficial influence of oral zinc supplementation on the reticulocyte count, but also on an increase in serum testosterone concentration and the alleviation of ED in this group of patients. ${ }^{47,48}$

The prevalence of depression among CKD patients may reach $20-30 \%{ }^{49,50}$ Depression can be another factor leading to the development of ED in this population. ${ }^{51}$ On the other hand, the treatment of depression with tricyclic antidepressants can exacerbate the course of ED in CKD patients. ${ }^{50}$

Chronic kidney disease is accompanied by many comorbidities. A vast proportion of these diseases can also be linked to the pathogenesis of ED. Globally, the most prevalent cause of kidney disease is diabetes mellitus. It is one of the most prominent risk factors for ED, as it causes autonomic neuropathy and vasculopathy as well as endothelial damage. ${ }^{52,53}$

Hypertension leads to the aggravation of atherosclerosis and endothelial dysfunction, so it can be considered as another risk factor for the development of ED. Despite strong evidence of such a relationship in the general population, ${ }^{54,55}$ the results of studies conducted on men with CKD are not fully conclusive. ${ }^{52,55}$ Medications commonly used in the treatment of hypertension, such as thiazide/ thiazide-like diuretics, most of beta-adrenergic receptor antagonists ( $\beta$-blockers) and alfa-2-adrenegic receptor antagonists $\left(\alpha_{2}\right.$-blockers) may contribute to the aggravation of ED in CKD men. ${ }^{56,57}$ On the other hand, the treatment with angiotensin-converting enzyme (ACE) inhibitors or angiotensin II type 1 receptor (AT1)-blockers seems to have some beneficial influence on the prevalence of ED in men on maintenance hemodialysis. ${ }^{53}$

Other risk factors for ED in CKD patients are obesity, especially with the body mass index (BMI) exceeding $28 \mathrm{~kg} / \mathrm{m}^{2}$, and dyslipidemia. ${ }^{58,59}$ Another important modifiable risk factor for atherosclerosis, and thus ED, is cigarette smoking. The results of studies conducted so far seem to imply that smokers are characterized by higher prevalence as well as magnitude of ED as compared to non-smokers. ${ }^{56,58}$

\section{Endocrine disorders in men with chronic kidney disease}

Men with CKD are characterized by several sex hormone derangements. Usually, the serum concentrations of both total testosterone (TT) and free testosterone (FT) 
are decreased, while the binding capacity and the serum sex hormone-binding globulin (SHBG) level remain normal. ${ }^{9}$ Additionally, serum LH concentration is elevated in uremic men, so hypergonadotropic hypogonadism can be diagnosed. It seems, though, that the main factor responsible for the low serum TT and FT concentrations is the uremia-related injury of the testes. On the other hand, the administration of human chorionic gonadotropin (HCG) in uremic subjects results in a blunted response in testosterone release. Human chorionic gonadotropin acts through a similar mechanism as LH, so hyporesponsiveness to $\mathrm{LH}$ in the uremic milieu can be diagnosed, which could suggest that it is rather the resistance of Sertoli cells to LH that causes low testosterone release. Interestingly, a compound blocking luteinizing hormone receptor (LHR) was found in uremic serum, yet so far only in in vitro conditions. ${ }^{60}$

Low serum testosterone concentrations in CKD may lead to diminished libido, but testosterone is also crucial in the correct functioning and morphology of the penis. Testosterone deficiency leads to the replacement of smooth muscle cells in the cavernous bodies with collagen fibers. ${ }^{61}$ This phenomenon directly links endocrine disturbances with ED, described in the previous paragraph. Interestingly, Fugl-Meyer et al. found no association between the CKD stage and/or serum TT concentration and the magnitude of sexual dysfunction in men, despite the fact that serum TT concentration decreased along with the stages of CKD. ${ }^{62}$

Besides the aforementioned elevation of serum LH concentration, also serum FSH concentration is increased in CKD males. This seems to be primarily caused by low serum inhibin concentration. Inhibin, which negatively regulates FSH release in the pituitary gland, is produced in Sertoli cells in the testes. ${ }^{63}$ Another hormone produced by Sertoli cells in males is AMH. Its serum concentration in men with terminal renal failure is decreased, as it was recently shown by Eckersten et al. ${ }^{64}$ Similarly to women, an increased serum concentration of PRL is often found in men with CKD. It is caused by increased production and decreased renal catabolism. ${ }^{9}$

It is important to stress that also the pharmacotherapy routinely used in men with CKD may contribute to changes in hormone concentrations and to the aggravation of fertility disorders. One of the potential examples is cinacalcet, widely used in the treatment of secondary hyperparathyroidism in CKD patients. Male patients treated with cinacalcet develop a decrease in the already low serum TT and FT concentrations. ${ }^{65}$ Moreover, it seems that cinacalcet treatment may further decrease the already abnormally low serum AMH concentration in this group of patients (data not yet published). On the other hand, the results of recent studies seem to suggest that transdermal testosterone replacement therapy (TRT) might be safe and effective in reversing the symptoms of testosterone deficiency, and improve quality of life in men with CKD. ${ }^{66}$

\section{Impaired spermatogenesis}

Chronic kidney disease is usually linked to the impairment of spermatogenesis. The analyses of semen in men with CKD usually show oligozoospermia, asthenozoospermia and a decrease in the ejaculate volume. Additionally, $\mathrm{Xu}$ et al. described vastly decreased sperm cell viability, motility and percentage of spermatozoa with normal morphology ${ }^{67}$ The fertility index (defined according to the Harvey formula: sperm concentration $\times$ sperm motility $\times$ percentage of spermatozoa with normal morphology) was strikingly, almost 60 times, lower than in the control group. Further ultrastructural examinations showed the abnormalities in the heads and tails of spermatozoa as well as the lack of acrosomes. ${ }^{67}$

In histological examinations, the atrophy of Sertoli cells was described. ${ }^{9}$ Further studies involving testicular biopsy analyses showed decreased germ cell proliferation and an increase in fibrosis in men with uremia. ${ }^{68}$ Moreover, men requiring maintenance dialysis develop a decrease in the testicular volume, which tends to progress along with the consecutive dialysis years. ${ }^{69}$ This is also reflected in a markedly decreased serum AMH concentration in men with CKD stage 5. Anti-Müllerian hormone in men is secreted by Sertoli cells to the bloodstream and the seminal fluid, and can be interpreted as a marker of the function of these cells. ${ }^{64}$

It is important to stress that several congenital conditions can be linked to the development of subfertility or infertility in CKD men. The presence of posterior urethral valves may be responsible for the pathogenesis of erectile and/or ejaculatory dysfunction even in young men. ${ }^{70}$ Also, autosomal dominant polycystic kidney disease (ADPKD) may be accompanied by, for example, seminal vessel cysts and/or asthenozoospermia. ${ }^{71}$

\section{Impaired fertility in men after kidney transplantation}

Kidney transplantation in adult male patients seems to alleviate the derangements in the hypothalamic-pituitary-gonadal axis caused by uremia. ${ }^{72,73}$ On the other hand, studies concerning testicular hormone concentration and the semen quality parameters yielded somewhat conflicting results. ${ }^{74,75}$

In a recent study by Eckersten et al., a rapid normalization of testosterone, LH and FSH as well as PRL was observed. ${ }^{76}$ However, no significant changes in serum AMH concentration and a decrease in serum inhibin B concentration were noted, ${ }^{76}$ suggesting that the Sertoli cell function does not improve as fast or to the same extent as the Leydig cell function.

Kidney transplantation does not fully nullify the morphological abnormalities of the testes and does not normalize the semen quality in comparison with healthy peers. Although an increase in the spermatogonium, spermatozoon and spermatocyte count was observed 
in the testicular biopsies of men before and after KTx, no increase in the Sertoli cell number was found. ${ }^{77}$ This is in line with a previously mentioned study by Eckersten et al. ${ }^{76}$ Moreover, in other studies, only slight improvement in the morphological image of the testicular biopsies was found in men after KTx treated with azathioprine, which raises the important question of the choice of the immunosuppression protocol in young kidney allograft recipients with reproductive plans.

Tainio et al. ${ }^{77}$ observed a smaller testes volume in men after successful KTx in childhood or adolescence in comparison with healthy controls. ${ }^{77}$ Also, the semen quality was worse, with only $22 \%$ of patients with normospermia. This was especially prominent in the subpopulation of men treated with cyclophosphamide in childhood. Interestingly, serum androgen concentrations in kidney allograft recipients and the general population were comparable. ${ }^{77}$

Successful KTx also tends to ameliorate ED, ${ }^{73}$ but the degree of improvement varies from more than $50 \%$ of patients in some studies, ${ }^{78}$ to no improvement or even worsening in others. ${ }^{79}$

\section{Effect of immunosuppression}

Calcineurin inhibitors (CNI) - cyclosporine A (CsA) and tacrolimus - seem not to have a significantly negative influence on male fertility, at least within therapeutic blood concentrations, ${ }^{65,79}$ even though animal studies showed a tendency to oligozoospermia, reduced sperm cell motility and altered testicular morphology under tacrolimus regimen. ${ }^{80,81}$ Reduced fertility in men after KTx can be attributed to mammalian target of rapamycin (mTOR) inhibitors - sirolimus and everolimus. Those compounds may interfere in the hypothalamus-pituitary-gonadal axis and may have a negative impact on the sperm cell count and motility. ${ }^{82,83}$ The effect of mycophenolate mofetil (MMF) and mycophenolic acid (MPA) on male fertility is not clear. Both MMF and MPA are teratogenic during pregnancy, but it seems that they have no profound negative impact on spermatogenesis and the paternity rate. ${ }^{84,85}$

\section{Conclusions}

Fertility disorders in women with CKD arise from a complex permeation of disturbances. Sexual function disorders, endocrine alterations with the prominent role of the hypothalamus-pituitary-ovarian axis disorders, reduced renal clearance of different hormones as well as the impairment of the ovarian function per se (e.g., a reduced ovarian reserve), all influence each other. These deteriorations together with the accumulation of uremic toxins form a composite network of disturbances, ultimately leading to the development of fertility impairment in women with CKD. In consequence, pregnancy is over 40 times rarer in women on prevalent hemodialysis than in the general population. Successful KTx in women with CKD reduces the accumulation of uremic toxins, restores the function of the endocrine system and improves fertility, but cannot reverse the damage already done to the ovaries by the uremic milieu, which is reflected by a reduced ovarian reserve. Thus, KTx vastly improves, but does not normalize fecundity in women with CKD.

Fertility disorders in men with CKD stem from a permeating network of 3 main disturbances. Erectile dysfunction, endocrine alterations with the prominent role of the hypothalamus-pituitary-testicular axis disorders and hypotestosteronemia, reduced renal clearance of different hormones as well as the direct impact of uremia on Sertoli and Leydig cells, leading to impaired spermatogenesis, all influence each other. Those deteriorations together with the accumulation of uremic toxins ultimately lead to the impairment of fertility in men with CKD. Successful KTx in men with CKD restores the function of the endocrine system and improves fertility up to a point, but cannot fully reverse the morphological damage already done to the gonads by uremia itself. Thus, also in CKD men, KTx improves, but does not normalize fecundity.

\section{ORCID iDs}

Piotr Kuczera (D) https://orcid.org/0000-0002-7526-978X Andrzej Więcek (1D https://orcid.org/0000-0002-8625-4188 Marcin Adamczak (D) https://orcid.org/0000-0002-0804-1718

\section{References}

1. Cochrane R, Regan L. Undetected gynaecological disorders in women with renal disease. Hum Reprod. 1997;12(4):667-670. doi:10.1093/ humrep/12.4.667

2. Anantharaman P, Schmidt RJ. Sexual function in chronic kidney disease. Adv Chronic Kidney Dis. 2007;14(2):119-125. doi:10.1053/j.ackd. 2007.01.002

3. Weisinger JR, Bellorin-Font E. Outcomes associated with hypogonadism in women with chronic kidney disease. Adv Chronic Kidney Dis. 2004;11(4):361-370. PMID:15492973.

4. Rizzoni G, Ehrich JH, Broyer M, et al. Successful pregnancies in women on renal replacement therapy: Report from the EDTA Registry. Nephrol Dial Transplant. 1992;7(4):279-287. doi:10.1093/oxfordjournals. ndt.a092129

5. Bagon JA, Vernaeve H, De Muylder X, Lafontaine JJ, Martens J, Van Roost G. Pregnancy and dialysis. Am J Kidney Dis. 1998;31(5):756-765. doi:10.1016/s0272-6386(98)70060-5

6. Watnick S. Pregnancy and contraceptive counseling of women with chronic kidney disease and kidney transplants. Adv Chronic Kidney Dis. 2007;14(2):126-131. doi:10.1053/j.ackd.2007.01.003

7. Vander Borght M, Wyns C. Fertility and infertility: Definition and epidemiology. Clin Biochem. 2018;62:2-10. doi:10.1016/j.clinbiochem. 2018.03.012

8. Dumanski SM, Ahmed SB. Fertility and reproductive care in chronic kidney disease. J Nephrol. 2019;32(1):39-50. doi:10.1007/s40620-01800569-9

9. Holley JL. The hypothalamic-pituitary axis in men and women with chronic kidney disease. Adv Chronic Kidney Dis. 2004;11(4):337-341. PMID:15492969.

10. Sikora-Grabka E, Adamczak M, Kuczera P, Szotowska M, Madej P, Wiecek A. Serum anti-Müllerian hormone concentration in young women with chronic kidney disease on hemodialysis, and after successful kidney transplantation. Kidney Blood Press Res. 2016;41(5): 552-560. doi:10.1159/000443458

11. Filocamo MT, Zanazzi M, Li Marzi V, et al. Sexual dysfunction in women during dialysis and after renal transplantation. J Sex Med. 2009;6(11):3125-3131. doi:10.1111/j.1743-6109.2009.01400.x 
12. Basok EK, Atsu N, Rifaioglu MM, Kantarci G, Yildirim A, Tokuc R. Assessment of female sexual function and quality of life in predialysis, peritoneal dialysis, hemodialysis, and renal transplant patients. Int Urol Nephrol. 2009;41(3):473-481. doi:10.1007/s11255-008-9475-z

13. Kettaş E, Çayan F, Akbay E, Kıykım A, Çayan S. Sexual dysfunction and associated risk factors in women with end-stage renal disease. JSexMed. 2008;5(3):872-877. doi:10.1111/j.1743-6109.2007.00664.x

14. Peng YS, Chiang CK, Kao TW, et al. Sexual dysfunction in female hemodialysis patients: A multicenter study. Kidney Int. 2005;68(2):760-765. doi:10.1111/j.1523-1755.2005.00454.x

15. Kaplan SA, Reis RB, Kohn IJ, et al. Safety and efficacy of sildenafil in postmenopausal women with sexual dysfunction. Urology. 1999; 53(3):481-486. doi:10.1016/s0090-4295(98)00633-5

16. Carrero JJ, Kyriazis J, Sonmez A, et al. Prolactin levels, endothelial dysfunction, and the risk of cardiovascular events and mortality in patients with CKD. Clin JAm Soc Nephrol. 2012;7(2):207-215. doi:10.2215 /CJN.06840711

17. Handelsman DJ, Dong Q. Hypothalamo-pituitary-gonadal axis in chronic renal failure. Endocrinol Metab Clin North Am. 1993;22(1): 145-161. PMID:8449185.

18. Sievertsen GD, Lim VS, Nakawatase C, Frohman LA. Metabolic clearance and secretion rates of human prolactin in normal subjects and in patients with chronic renal failure. J Clin Endocrinol Metab. 1980; 50(5):846-852. doi:10.1210/jcem-50-5-846

19. Kokot F, Wiecek A, Schmidt-Gayk H, et al. Influence of long-term erythropoietin therapy on endocrine abnormalities in haemodialyzed patients. Przegl Lek. 1992;49(1-2):43-49. PMID:1455006.

20. Ros S, Carrero JJ. Endocrine alterations and cardiovascular risk in CKD: Is there a link? Nefrologia. 2013;33(2):181-187. doi:10.3265/Nefrologia. pre2012.Oct.11710

21. Swamy AP, Woolf PD, Cestero RV. Hypothalamic-pituitary-ovarian axis in uremic women. J Lab Clin Med. 1979;93(6):1066-1072. PMID: 438608.

22. Sugiya N, Nakashima A, Takasugi N, et al. Endogenous estrogen may prevent bone loss in postmenopausal hemodialysis patients throughout life. Osteoporos Int. 2011;22(5):1573-1579. doi:10.1007/ s00198-010-1350-y

23. Nagatoya K, Nishimoto K, Shibahara N, et al.; Hokusetsu Renal Osteodystrophy Study Group. Effects of raloxifene on bone metabolism in postmenopausal women on chronic hemodialysis. Clin Exp Nephrol. 2015;19(5):939-946. doi:10.1007/s10157-014-1065-z

24. Wilkosz P, Greggains GD, Tanbo TG, Fedorcsak P. Female reproductive decline is determined by remaining ovarian reserve and age. PLoS One. 2014;9(10):e108343. doi:10.1371/journal.pone.0108343

25. Durlinger ALL, Visser JA, Themmen APN. Regulation of ovarian function: The role of anti-Müllerian hormone. Reproduction. 2002;124(5): 601-609. doi:10.1530/rep.0.1240601

26. Jeppesen JV, Anderson RA, Kelsey TW, et al. Which follicles make the most anti-Müllerian hormone in humans? Evidence for an abrupt decline in $\mathrm{AMH}$ production at the time of follicle selection. Mol Hum Reprod. 2013;19(8):519-527. doi:10.1093/molehr/gat024

27. Grynnerup AGA, Lindhard A, Sørensen S. The role of anti-Müllerian hormone in female fertility and infertility: An overview. Acta Obstet Gynecol Scand. 2012;91(11):1252-1260. doi:10.1111/j.1600-0412. 2012.01471.x

28. La Marca A, Stabile G, Artenisio AC, Volpe A. Serum anti-Müllerian hormone throughout the human menstrual cycle. Hum Reprod. 2006:21(12):3103-3107. doi:10.1093/humrep/del291

29. Kalaiselvi VS, Saikumar P, Prabhu K, Prashanth Krishna G. The antiMüllerian hormone: A novel marker for assessing the ovarian reserve in women with regular menstrual cycles. J Clin Diagn Res. 2012;6(10):1636-1639. doi:10.7860/JCDR/2012/5101.2624

30. Younis JS. Ovarian aging and implications for fertility female health. Minerva Endocrinol. 2012;37(1):41-57. PMID:22382614.

31. Szydłowska I, Marciniak A, Brodowska A, Lisak M, Przysiecka S, Różański J. Assessment of ovarian reserve as an indicator of fertility and health consequences in patients with chronic kidney disease stages 3-4. Gynecol Endocrinol. 2018;34(11):944-948. doi:10.1080/09513 590.2018 .1473364

32. Stoumpos S, Lees J, Welsh $\mathrm{P}$, et al. The utility of anti-Müllerian hormone in women with chronic kidney disease, on haemodialysis and after kidney transplantation. Reprod Biomed Online. 2018;36(2):219-226. doi:10.1016/j.rbmo.2017.11.003
33. Pietrzak B, Cyganek A, Jabiry-Zieniewicz Z, et al. Function of the ovaries in female kidney transplant recipients. Transplant Proc. 2006; 38(1):180-183. doi:10.1016/j.transproceed.2005.12.045

34. Sikora-Grabka E, Adamczak M, Kuczera P, Więcek A. Serum sex hormones concentrations in young women in the early period after successful kidney transplantation. Endokrynol Pol. 2018;69(2):150-155. doi:10.5603/EP.2018.0019

35. Agarwal A, Mulgund A, Hamada A, Chyatte MR. A unique view on male infertility around the globe. Reprod Biol Endocrinol. 2015;13:37. doi:10.1186/s12958-015-0032-1

36. Navaneethan SD, Vecchio M, Johnson DW, et al. Prevalence and correlates of self-reported sexual dysfunction in CKD: A meta-analysis of observational studies. Am J Kidney Dis. 2010;56(4):670-685. doi:10. 1053/j.ajkd.2010.06.016

37. Pereira Mesquita JF, Ramos TF, Pereira Mesquita F, Bastos Netto JM, Bastos MG, de Figueiredo AA. Prevalence of erectile dysfunction in chronic renal disease patients on conservative treatment. Clinics (Sao Paulo). 2012;67(2):181-183. doi:10.6061/clinics/2012(02)15

38. Burnett $A L$, Musicki $B$. The nitric oxide signaling pathway in the penis. Curr Pharm Des. 2005;11(31):3987-3994. doi:10.2174/138161205774 913381

39. Burnett AL, Tillman SL, Chang TS, et al. Immunohistochemical localization of nitric oxide synthase in the autonomic innervation of the human penis. J Urol. 1993;150(1):73-76. doi:10.1016/s0022-5347 (17)35401-0

40. Finberg JP, Levy S, Vardi Y. Inhibition of nerve stimulation-induced vasodilatation in corpora cavernosa of the pithed rat by blockade of nitric oxide synthase. Br J Pharmacol. 1993;108(4):1038-1042. doi:10.1111/j.1476-5381.1993.tb13502.x

41. Schaefer RM, Kokot F, Wernze H, Geiger H, Heidland A. Improved sexual function in hemodialysis patients on recombinant erythropoietin: A possible role for prolactin. Clin Nephrol. 1989;31(1):1-5. PMID:2914405.

42. Bommer J, Kugel M, Schwöbel B, Ritz E, Barth HP, Seelig R. Improved sexual function during recombinant human erythropoietin therapy. Nephrol Dial Transplant. 1990;5(3):204-207. doi:10.1093/ndt/5.3.204

43. Watschinger B, Watzinger U, Templ H, Spona J, Graf H, Luger A. Effect of recombinant human erythropoietin on anterior pituitary function in patients on chronic hemodialysis. Horm Res. 1991;36(1-2):22-26. doi:10.1159/000182100

44. Schaefer F, van Kaick B, Veldhuis JD, et al. Changes in the kinetics and biopotency of luteinizing hormone in hemodialyzed men during treatment with recombinant human erythropoietin. J Am Soc Nephrol. 1994;5(5):1208-1215. doi:10.1681/ASN.V551208

45. Parsa CJ, Matsumoto A, Kim J, et al. A novel protective effect of erythropoietin in the infarcted heart. J Clin Invest. 2003;112(7):999-1007. doi:10.1172/JCl18200

46. Sakanaka M, Wen TC, Matsuda S, et al. In vivo evidence that erythropoietin protects neurons from ischemic damage. Proc Natl Acad Sci U SA. 1998;95(8):4635-4640. doi:10.1073/pnas.95.8.4635

47. Fukushima T, Horike H, Fujiki S, Kitada S, Sasaki T, Kashihara N. Zinc deficiency anemia and effects of zinc therapy in maintenance hemodialysis patients. Ther Apher Dial. 2009;13(3):213-219. doi:10.1111/j.17449987.2009.00656.x

48. Mahajan SK, Abbasi AA, Prasad AS, Rabbani P, Briggs WA, McDonald FD. Effect of oral zinc therapy on gonadal function in hemodialysis patients: A double-blind study. Ann Intern Med. 1982;97(3):357-361. doi:10.7326/0003-4819-97-3-357

49. Weisbord SD, McGill JB, Kimmel PL. Psychosocial factors in patients with chronic kidney disease. Adv Chronic Kidney Dis. 2007;14(4):316-318. doi:10.1053/j.ackd.2007.07.012

50. Segraves RT, Balon R. Antidepressant-induced sexual dysfunction in men. Pharmacol Biochem Behav. 2014;121:132-137. doi:10.1016/j. pbb.2013.11.003

51. Peng YS, Chiang CK, Hung KY, et al. The association of higher depressive symptoms and sexual dysfunction in male haemodialysis patients. Nephrol Dial Transplant. 2007;22(3):857-861. doi:10.1093/ ndt/gfl666

52. Neto AF, de Freitas Rodrigues MA, Saraiva Fittipaldi JA, Moreira ED Jr. The epidemiology of erectile dysfunction and its correlates in men with chronic renal failure on hemodialysis in Londrina, southern Brazil. Int J Impot Res. 2002;14(Suppl 2):S19-S26. doi:10.1038/sj.ijir. 3900894 
53. Giuliano FA, Leriche A, Jaudinot EO, de Gendre AS. Prevalence of erectile dysfunction among 7689 patients with diabetes or hypertension, or both. Urology. 2004;64(6):1196-1201. doi:10.1016/j.urology. 2004.08.059

54. Cerqueira J, Moraes M, Glina S. Erectile dysfunction: Prevalence and associated variables in patients with chronic renal failure. Int J Impot Res. 2002;14(2):65-71. doi:10.1038/sj.ijir.3900811

55. Ponholzer A, Temml C, Mock K, Marszalek M, Obermayr R, Madersbacher $S$. Prevalence and risk factors for erectile dysfunction in 2869 men using a validated questionnaire. Eur Urol. 2005;47(1):80-86. doi:10.1016/j.eururo.2004.08.017

56. Chrysant SG. Antihypertensive therapy causes erectile dysfunction Curr Opin Cardiol. 2015;30(4):383-390. doi:10.1097/HCO.0000000000 000189

57. Kupelian V, Hall SA, McKinlay JB. Common prescription medication use and erectile dysfunction: Results from the Boston Area Community Health (BACH) survey. BJU Int. 2013;112(8):1178-1187. doi:10.1111/ bju.12231

58. Feldman HA, Johannes CB, Derby CA, et al. Erectile dysfunction and coronary risk factors: Prospective results from the Massachusetts male aging study. Prev Med. 2000;30(4):328-338. doi:10.1006/pmed. 2000.0643

59. Fung MM, Bettencourt R, Barrett-Connor E. Heart disease risk factors predict erectile dysfunction 25 years later: The Rancho Bernardo Study. J Am Coll Cardiol. 2004;43(8):1405-1411. doi:10.1016/j. jacc.2003.11.041

60. Dunkel L, Raivio T, Laine J, Holmberg C. Circulating luteinizing hormone receptor inhibitor(s) in boys with chronic renal failure. Kidney Int. 1997;51(3):777-784. doi:10.1038/ki.1997.109

61. Shen ZJ, Zhou XL, Lu YL, Chen ZD. Effect of androgen deprivation on penile ultrastructure. Asian J Androl. 2003;5(1):33-36. PMID:12647000.

62. Fugl-Meyer KS, Nilsson M, Hylander B, Lehtihet M. Sexual function and testosterone level in men with conservatively treated chronic kidney disease. Am J Mens Health. 2017;11(4):1069-1076. doi:10.1177/ 1557988317703207

63. Chryssicopoulos A, Koutsikos D, Kapetanaki A, et al. Evaluation of the hypothalamic-pituitary axis in uremic males using dynamic tests. The possible role of testicular inhibin: A preliminary report. Ren Fail. 1996;18(6):911-921. doi:10.3109/08860229609047717

64. Eckersten D, Giwercman A, Bruun L, Christensson A. Anti-Müllerian hormone, a Sertoli cell-derived marker, is decreased in plasma of male patients in all stages of chronic kidney disease. Andrology. 2015;3(6):1160-1164. doi:10.1111/andr.12116

65. Kuczera P, Adamczak M, Więcek A. Changes of serum total and free testosterone concentrations in male chronic hemodialysis patients with secondary hyperparathyroidism in response to cinacalcet treatment. Kidney Blood Press Res. 2016;41(1):1-8. doi:10.1159/000368541

66. Yeo JK, Koo HS, Yu J, Park MG. Effects of testosterone treatment on quality of life in patients with chronic kidney disease. Am JMens Health. 2020;14(3):1557988320917258. doi:10.1177/1557988320917258

67. Xu LG, Shi SF, Qi XP, et al. Morphological characteristics of spermatozoa before and after renal transplantation. Asian J Androl. 2005;7(1): 81-85. doi:10.1111/j.1745-7262.2005.00002.x

68. Shiraishi K, Shimabukuro T, Naito K. Effects of hemodialysis on testicular volume and oxidative stress in humans. J Urol. 2008;180(2): 644-650. doi:10.1016/j.juro.2008.04.010

69. Xu HM, Li HG, Xu LG, Zhang JR, Chen WY, Shi QX. The decline of fertility in male uremic patients is correlated with low expression of the cystic fibrosis transmembrane conductance regulator protein (CFTR) in human sperm. Hum Reprod. 2012;27(2):340-348. doi:10.1093 /humrep/der403
70. Woodhouse CR, Reilly JM, Bahadur G. Sexual function and fertility in patients treated for posterior urethral valves. JUrol. 1989;142(2 Pt 2): 586-588;discussion 603-605. doi:10.1016/s0022-5347(17)38824-9

71. Luciano RL, Dahl NK. Extra-renal manifestations of autosomal dominant polycystic kidney disease (ADPKD): Considerations for routine screening and management. Nephrol Dial Transplant. 2014;29(2): 247-254. doi:10.1093/ndt/gft437

72. Prem AR, Punekar SV, Kalpana M, Kelkar AR, Acharya VN. Male reproductive function in uraemia: Efficacy of haemodialysis and renal transplantation. Br J Urol. 1996;78(4):635-638. doi:10.1046/j.1464410x.1996.14624.x

73. Akbari $F$, Alavi $M$, Esteghamati $A$, et al. Effect of renal transplantation on sperm quality and sex hormone levels. BJU Int. 2003;92(3): 281-283. doi:10.1046/j.1464-410x.2003.04323.x

74. Tauchmanovà L, Carrano R, Sabbatini M, et al. Hypothalamic-pituitary-gonadal axis function after successful kidney transplantation in men and women. Hum Reprod. 2004;19(4):867-873. doi:10.1093/ humrep/deh192

75. Bozzini G, Lunelli L, Berlingheri M, Groppali E, Carmignani L. Epididymis microlithiasis and semen abnormalities in young adult kidney transplant recipients. Andrologia. 2013:45(5):357-360. doi:10.1111/ and. 12036

76. Eckersten D, Giwercman A, Pihlsgård M, Bruun L, Christensson A Impact of kidney transplantation on reproductive hormone levels in males: A longitudinal study. Nephron. 2018;138(3):192-201. doi:10. 1159/000484992

77. Tainio J, Jahnukainen $\mathrm{K}$, Nurmio $M$, Pakarinen $M$, Jalanko $H$, Jahnukainen T. Testicular function, semen quality, and fertility in young men after renal transplantation during childhood or adolescence. Transplantation. 2014:98:987-993. doi:10.1097/TP.0000000000000173

78. Shamsa A, Motavalli SM, Aghdam B. Erectile function in end-stage renal disease before and after renal transplantation. Transplant Proc. 2005;37(7):3087-3089. doi:10.1016/j.transproceed.2005.08.067

79. Mirone V, Longo N, Fusco F, et al. Renal transplantation does not improve erectile function in hemodialysed patients. Eur Urol. 2009; 56(6):1047-1053. doi:10.1016/j.eururo.2008.09.020

80. Haberman J, Karwa G, Greenstein SM, et al. Male fertility in cyclosporine-treated renal transplant patients. J Urol. 1991;145(2):294-296. doi:10.1016/s0022-5347(17)38318-0

81. Caneguim BH, Cerri PS, Spolidório LC, Miraglia SM, Sasso-Cerri E. Structural alterations in the seminiferous tubules of rats treated with immunosuppressor tacrolimus. Reprod Biol Endocrinol. 2009;7:19. doi:10.1186/1477-7827-7-19

82. Tondolo V, Citterio F, Panocchia N, Nanni G, Castagneto M. Sirolimus impairs improvement of the gonadal function after renal transplantation. Am J Transplant. 2005;5(1):197. doi:10.1111/j.1600-6143. 2005.00604.x

83. Zuber J, Anglicheau D, Elie C, et al. Sirolimus may reduce fertility in male renal transplant recipients. Am J Transplant. 2008;8(7): 1471-1479. doi:10.1111/j.1600-6143.2008.02267.x

84. Jones A, Clary MJ, McDermott E, et al. Outcomes of pregnancies fathered by solid-organ transplant recipients exposed to mycophenolic acid products. Prog Transplant. 2013;23(2):153-157. doi:10.7182/ pit2013636

85. Midtvedt K, Bergan S, Reisæter AV, Vikse BE, Åsberg A. Exposure to mycophenolate and fatherhood. Transplantation. 2017;101(7): e214-e217. doi:10.1097/TP.0000000000001747 